\title{
DAILY RUNOFF SIMULATION IN RAVANSAR SANJABI BASIN, KERMANSHAH, IRAN, USING REMOTE SENSING THROUGH SRM MODEL AND COMPARISON TO SWAT MODEL
}

\author{
ShahoeI, S. V. ${ }^{1}$ - Porhemmat, J $^{2^{*}}-$ Sedghi, H. ${ }^{1}-$ Hosseini, M. ${ }^{2}-$ SAREMI, A. ${ }^{1}$ \\ ${ }^{I}$ Department of Water Science and Engineering, Science and Research Branch, \\ Islamic Azad University, Tehran, Iran \\ e-mail:Vahid.shahoei@gmail.com; hsedgh@yahoo.com; saremi.ptmco@gmail.com \\ ${ }^{2}$ Soil Conservation and Watershed Management Research Institute, Tehran, Iran \\ e-mail:jahanpor@yahoo.com; mjhossaini@gmail.com \\ *Corresponding author \\ e-mail:jahanpor@yahoo.com \\ phone: +98-912-390-2521
}

(Received 25 $5^{\text {th }}$ Mar 2017; accepted $3^{\text {rd }}$ Jun 2017)

\begin{abstract}
In this paper the daily runoff of Ravansar Sanjabi basin, Kermanshah, Iran is simulated through SRM and SWAT models. SRM is a deterministic and degree-day based model which simulates or forecasts the daily runoff in mountain basins through Snow Cover Area (SCA) variable and also other meteorological data such as rainfall and temperature. The images of Snow Covered Area obtained from MOD10A2 of the MODIS satellite are used to calculate the SCA as a key variable for SRM in this study. On the other hand, SWAT model is a continuous and distributive model which can simulate the hydrological processes in basins through a wide range of information such as physical information of basins (soil, land use, slope) as well as weather data such as precipitation, temperature, wind, relative humidity, solar radiation. Simulation results during the calibration and validation periods are evaluated through three statistical indices: Nash-Sutcliffe efficiency (NSE) coefficient, coefficient of determination, and volume difference. Comparison of simulated and observed flow hydrographs and calculated statistical coefficients show that SRM model results are acceptable in simulating daily runoff for both calibration and validation periods (NSE: 0.9 and 0.95 respectively); while SWAT model presents weak results (NSE: 0.14 and 0.16 , respectively).
\end{abstract}

Keywords: hydrological model, discharge prediction, snowmelt, GIS, snow cover map, calibration, validation

\section{Introduction}

In recent years, the use of hydrological models, as a useful tool in understanding the natural processes that occur in watersheds, has increased and therefore, many numerical models have been developed for use in hydrological and water resources studies. These models are utilized in assessing the quantity and quality of river flow, flood forecasting, development and protection of water resources, integrated management of surface and ground water, water distribution system, effects of climate change, land use change, and most of water resource management measures (Wurbs, 1998; Singh and Woolhiser, 2002). In most of the basins that require water resource planning, there is a lack of hydrometric stations for surface runoff measurement, or the data of measurement stations are incomplete; it is also unlikely to have measurement stations in all regions in the near future. Hydrological models, therefore, can evaluate the obtained runoff from precipitation (snow or rain) in basins with no or incomplete surface runoff data with minimal cost and time by simulating the rainfall-runoff process. The snow and snow 
melting runoff should be considered in hydrological, climatological, and hydrometeorological studies, forecast and simulation of flood, especially in mountainous areas (Tekeli et al., 2005). The accumulated snow in the mountains can be a major source of river flow in basins. Therefore, simulation of the hydrological processes that occur in mountainous basins is necessary for water resources management, as well as the local and regional economies (Fontaine et al., 2002).

\section{Review of Literature}

Snowmelt Runoff Model (SRM) is a degree-day based conceptual and deterministic model which is created to simulate or forecast the daily runoff in mountainous basins, where the snowmelt is the major factor of runoff (Martinec et al., 2008). This model was initially developed for a number of small basins in Europe (Martinec, 1975), but its application has been nowadays increased due to the expansion of remote sensing technologies and satellite imagery; hence, it can be applied for basins of different areas and shapes. In this regard, the SRM is well applied in basins with areas of $0.29 \mathrm{~km}^{2}$ to $917444 \mathrm{~km}^{2}$ (Martinec et al., 2008). Wang and Li (2006) considered this model as the most successful snowmelt runoff model. Gomez-Landesa and Rango (2002) simulated the snow melt runoff in three basins with different areas in Pyrenees Mountains through SRM model. Results of their study indicated appropriate runoff simulation by SRM in basin with an area of more than $572.9 \mathrm{~km}^{2}$, such that the volume difference of simulated and observed flow was about $8.9 \%$. In two other studied basins with smaller areas $\left(38.1 \mathrm{~km}^{2}\right.$ and $\left.23.1 \mathrm{~km}^{2}\right)$, the volume difference of simulated and observed flow was more than those obtained from larger basin; and the simulated runoff was significantly smaller than the observed amount due to the inadequacy and use of average precipitation and temperature. Using the images of Snow Cover Area $(S C A)$ by two satellites, MODIS and NOHRSC, Lee et al. (2005) simulated the runoff through SRM model in Rio Grand and Rio Ojo basins, located in Colorado and New Mexico of U.S.A. Results showed that the SRM model could be used successfully for runoff simulation in Rio Grand basin, with the volume difference between simulated and observed flow using SCA images of MODIS and NOHRSC satellites being about $2.6 \%$ and $14 \%$, respectively. The flow simulation conducted by SRM through products of both satellites is not satisfactory in Rio Ojo basin, such that the volume difference between simulated and observed flow was $-33.1 \%$ and $-18.6 \%$, respectively. Furthermore, they simulated the snow-equivalent water for the third elevation zone through SRM and compared it with the measured values, and concluded that the snowequivalent water simulated by SRM matches the measured values per images of both satellites. Tahir et al. (2011) simulated daily runoff in Hunza river basin in northern Pakistan using SRM model. Their research results indicated that the SRM has high efficiency for simulating the runoff in this basin, such that the Nash-Sutcliffe efficiency coefficient (NSE) and volume difference $\left(D_{v}\right)$ between simulated and observed flow for the calibration period were equal to $0.9 \%$ and $-2.6 \%$, respectively. In validation step, which included three different periods, the NSE coefficient were equal to $0.94,0.92$, 0.83 , and the calculated volume difference $\left(D_{v}\right)$, were $3 \%, 1.2 \%$ and $8.1 \%$. Furthermore, they predicted the flow under different climate change scenarios using the SRM model and proposed a creation of new reservoirs on the rivers to supply water for irrigation, hydroelectric plants, as well as flood control by saving the summer flow. Karimi et al. (2016) compared and evaluated the results of simulated snow melt by both the Wetspa 
and the SRM models in the Horo-Dehno basin, located in the Lorestan Province of Iran. It was found that the WetSpa model simulates the snow melt runoff more efficiently than the SRM model in this basin, with the Nash-Sutcliffe coefficient for the SRM model being 0.54 and 0.53 in calibration and validation periods, respectively; while the corresponding Nash-Sutcliffe coefficient for the WetSpa model in the calibration and validation periods were determined as 0.77 and 0.8 , respectively. Similar studies have been done by Feng et al. (2000), Ma and Cheng (2003), Liu et al. (2007), Zhang et al. (2009), Sensoy and Uysal (2012), Safari Shad et al. (2013), Kult et al. (2104), and Vafakhah et al. (2014).

One of the most popular hydrological models for runoff simulation amongst researchers is the Soil and Water Assessment Tool (SWAT). SWAT model, introduced by Arnold et al. (1998) and further developed by Arnold and Forher (2005), is a conceptual, continuous and distributive model that can simulate hydrological processes in basins of small, medium and large scales. This model can be run on daily and hourly time scales and can simulate all components of water balance (Arnold et al., 1998). Due to the applicability of this model in complex basins, i.e. large basins with more than 100 sub-basins (Kusre et al., 2010), its use is increasing in managerial measures in basins such as pollution control, examining the impact of climate change, and management of water resources. Several studies have been conducted on different basins using SWAT model. Li et al. (2007) adopted this model to a basin located in West Africa and found that alteration of areas with forest, grassland and shrubbery land use to agricultural lands or urban areas will change the natural hydrological conditions in a basin. This change will lead to an increase in volume of surface runoff, reduction in groundwater resources and base flow of rivers. Mishra et al. (2007) simulated the runoff and sediment at daily and monthly time scales in a small basin in India using the SWAT model. Results showed that the model estimated the simulated values more than the observed ones during the validation period; and the volume of surface runoff, especially in the daily time scale, had less accuracy as compared to the calibration period. Rostamian et al. (2008) used the SWAT model for estimating runoff and sediment in Beheshtabad Basin, located in North Karun, Iran. The results of the model were satisfactory for average monthly runoff in calibration and validation periods, and it was found that the model predicted runoff better than sediment. Oeurng et al. (2011) simulated runoff and sediment using the SWAT model in a large basin with an area of $1110 \mathrm{~km}^{2}$ in south-western France. Results of this study showed that the SWAT model is able to simulate the runoff and sediment in large basins. Using a comparative study, Sommerlot et al. (2013) compared the accuracy of three hydrological models, namely SWAT, HIT and RUSLE2 in simulation of hydrological processes at basin scale by Pfactor and R-factor statistics. The results of this study indicated that SWAT model with P-factor of 0.51 and R-factor of 0.31 has the highest accuracy among the 3 models. Murty et al. (2014) simulated the water balance of Ken basin in India by SWAT model. The simulation results indicated the suitability of SWAT model in simulation of hydrological processes in this basin. Similar studies (Peterson and Hamlett, 1998; Spruill et al., 2000; Varanou et al., 2002; Hosseini, 2010; Jain et al., 2010; Hosseini and Ashraf, 2015) have confirmed the satisfactory use of the SWAT model in simulation of hydrological processes.

Since it is impossible to measure all necessary quantities for analyzing the runoff in basins, it is essential to choose a model which can accurately simulate the runoff by using minimum data. In this regard, a comparative study between hydrological models 
can help to choose the best model for runoff simulation in basins. In this study, the daily runoff is simulated in Ravansar Sanjabi basin by means of SWAT and SRM models. The latter has been selected due to the mountainous area of the basin, the direct input of $S C A$ images and direct inclusion of snow melt runoff as input, while the former is used due to its high performance in terms of including a wide variety of parameters (e.g. soil, land use and DEM maps, etc.) as input data. Results of these models are evaluated in daily runoff simulation through statistical criteria to select the most suitable model.

\section{Materials and Methods}

\section{Location of Study}

Ravansar Sanjabi basin, with geographical coordinates extending from $46^{\circ} 21^{\prime} 30^{\prime \prime} \mathrm{E}$ to $46^{\circ} 49^{\prime} 30^{\prime \prime} \mathrm{E}$ and $34^{\circ} 20^{\prime} 0^{\prime \prime} \mathrm{N}$ to $34^{\circ} 60^{\prime} 0^{\prime \prime} \mathrm{N}$ located in Kermanshah, Iran with an area of $1260 \mathrm{Km}^{2}$, is one of the sub-basins of the Karkhe catchment. The main river forming this basin is the Gareh Sou River, which in turn has its own main source of Ravansar mirage, located at $50 \mathrm{~km}$ of north-west Kermanshah. The geographical location of Ravansar Sanjabi watershed is shown in Fig. 1.

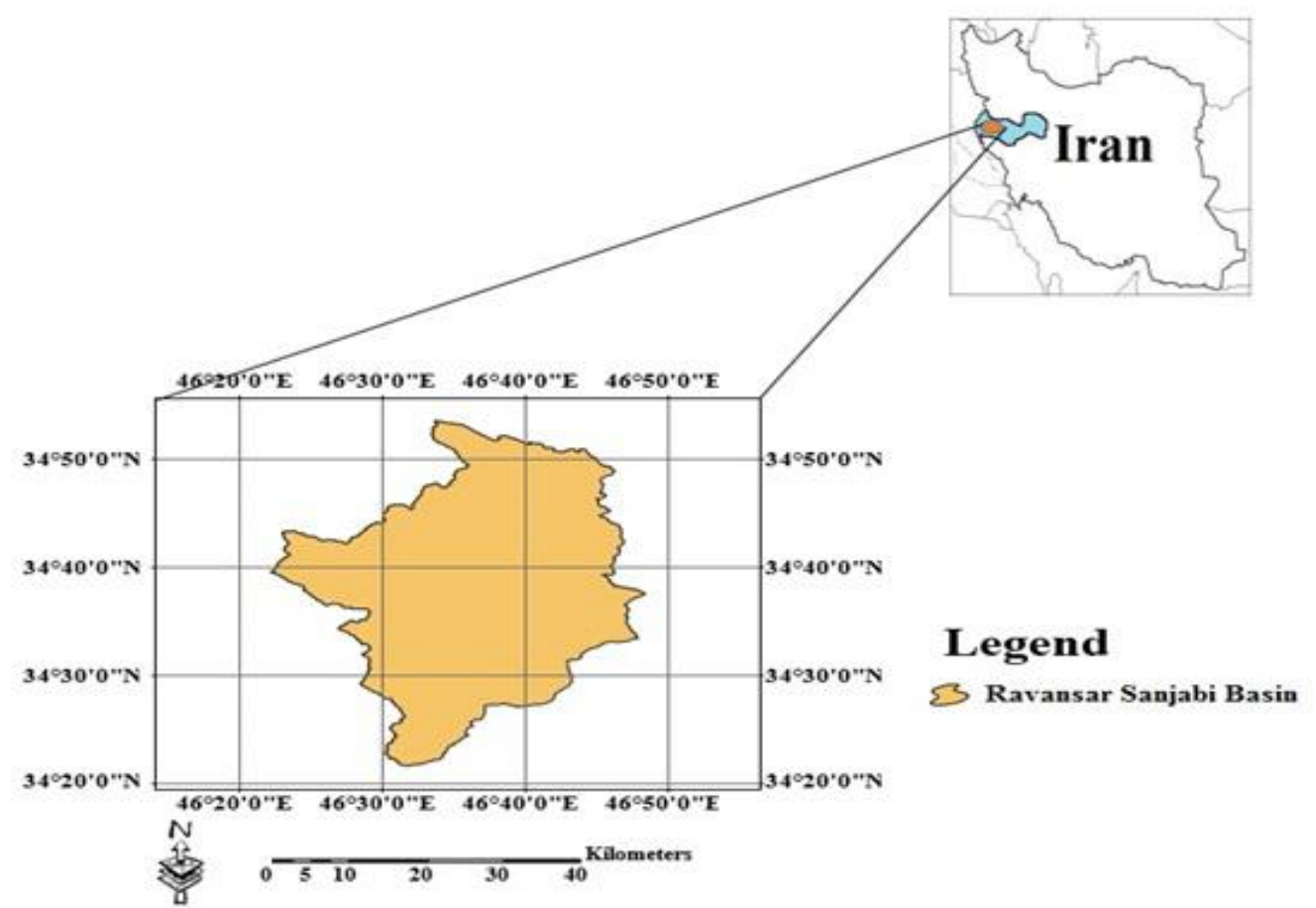

Figure 1. Shape and geographical location of Ravansar Sanjabi basin

\section{Used Hydro-Meteorological Data}

Two time periods of daily hydro-meteorological data are utilized in this study (from January 2002 to December 2003). The daily rainfall and temperature data of synoptic and meteorological stations, as well as the runoff data of Doab Merk hydrometric station as the output of basin, are used as the input variables for simulation of daily runoff using the SRM model. On the other hand, the SWAT model requires input data 
of rainfall, temperature, wind, relative humidity, and solar daily radiation of synoptic and meteorological stations for daily runoff simulation. Table 1 shows the hydrometric, synoptic and meteorological stations used in the study for the Ravansar Sanjabi basin.

Table 1. Geographical coordinates and details of meteorological and hydrometric stations used in the study

\begin{tabular}{ccccc} 
Station & Type & Elevation $(\boldsymbol{m})$ & Latitude & Longitude \\
\hline Doab Merek & Hydrometric & 1339 & $34^{\circ} 33^{\prime} 00^{\prime \prime}$ & $46^{\circ} 46^{\prime} 59^{\prime \prime}$ \\
Ravansar & synoptic & 1363 & $34^{\circ} 43^{\prime} 0^{\prime \prime}$ & $46^{\circ} 40^{\prime} 0^{\prime \prime}$ \\
Bencheleh & Typical rain gage & 1700 & $34^{\circ} 47^{\prime} 58^{\prime \prime}$ & $46^{\circ} 35^{\prime} 13^{\prime \prime}$ \\
Koozaran & Meteorological rain gauge & 1401 & $34^{\circ} 39^{\prime} 0^{\prime \prime}$ & $46^{\circ} 36^{\prime} 0^{\prime \prime}$ \\
Nahrabi & Meteorological rain gauge & 1490 & $34^{\circ} 40^{\prime} 0^{\prime \prime}$ & $46^{\circ} 34^{\prime} 0^{\prime \prime}$ \\
\hline
\end{tabular}

\section{Spatial Maps}

The necessary spatial maps for the SWAT model include Digital Elevation Map (DEM), soil and land use maps. The DEM map of Ravansar Sanjabi basin is obtained by converting the topographic map with scale of 1:25000 in the target basin into DEM with a cell size of 85 using ARCGIS 10.1. The soil and land use maps of Ravansar Sanjabi basin were prepared from Soil Conservation and Watershed Management Research Institute (SCWMRI). The DEM map, and the raster soil and land use maps of Ravansar Sanjabi basin are shown in Fig. 2.

According to data obtained from land use and soil maps in this area (Fig. 2), there are 12 soil types and 17 land use and land cover categories in Ravansar Sanjabi basin, which should be introduced into the SWAT model. Table 2 and Table 3 shows soil characteristics and landuse or landcover types in Ravansar Sanjabi basin, respectively.

Table 2. Soil characteristics in the Ravansar Sanjabi basin

\begin{tabular}{ccccc}
$\begin{array}{c}\text { Soils in } \\
\text { Basin }\end{array}$ & $\begin{array}{c}\text { The numbers of } \\
\text { soil layers }\end{array}$ & Hydrologic group & Soil texture & $\begin{array}{c}\text { The depth of root } \\
\text { penetration }(\mathbf{c m})\end{array}$ \\
\hline Soil 1 & 3 & C & C-Cl-SCL & 150 \\
Soil 2 & 1 & D & C & 30 \\
Soil 3 & 3 & A & SCL-C-C & 180 \\
Soil 4 & 1 & D & C & 35 \\
Soil 5 & 3 & D & SC-C-C & 150 \\
Soil 6 & 1 & D & CL & 30 \\
Soil 7 & 3 & B & CL-SCL-C & 110 \\
Soil 8 & 1 & B & C & 35 \\
Soil 9 & 3 & C & C-CL-C & 120 \\
Soil 10 & 2 & A & C-C & 150 \\
Soil 11 & 1 & D & C-SCL-CL & 150 \\
Soil 12 & 2 & B & CL-SCL & 150 \\
& & & &
\end{tabular}


Table 3. Land use and land cover in the Ravansar Sanjabi basin

\begin{tabular}{|c|c|c|c|c|c|}
\hline Number & $\begin{array}{l}\text { Land use/Land } \\
\text { cover }\end{array}$ & Number & $\begin{array}{c}\text { Land use/Land } \\
\text { cover }\end{array}$ & Number & $\begin{array}{c}\text { Land use/Land } \\
\text { cover }\end{array}$ \\
\hline 1 & Medium rangeland & 7 & Water & 13 & $\begin{array}{l}\text { Mixed medium } \\
\text { forest and good } \\
\text { rangeland }\end{array}$ \\
\hline 2 & $\begin{array}{l}\text { Mixed rain-fed and } \\
\text { irrigated agriculture }\end{array}$ & 8 & $\begin{array}{l}\text { Mixed rain-fed and } \\
\text { irrigated agriculture } \\
\text { and Medium } \\
\text { rangeland }\end{array}$ & 14 & $\begin{array}{l}\text { Mixed irrigated farm } \\
\text { and garden }\end{array}$ \\
\hline 3 & $\begin{array}{l}\text { Mixed irrigated } \\
\text { agriculture and }\end{array}$ & 9 & Irrigated agriculture & 15 & $\begin{array}{l}\text { Mixed Poor forest } \\
\text { and poor rangeland }\end{array}$ \\
\hline 4 & $\begin{array}{l}\text { Medium rangeland } \\
\text { Mixed irrigated } \\
\text { agriculture and poor } \\
\text { rangeland }\end{array}$ & 10 & Stones and rocks & 16 & Dense forest \\
\hline 5 & Urban & 11 & Poor forest & 17 & Medium forest \\
\hline 6 & Poor rangeland & 12 & Good rangeland & & \\
\hline
\end{tabular}

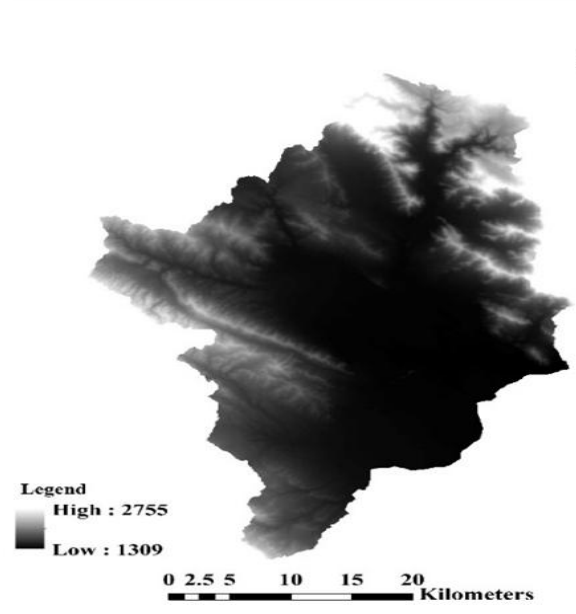

(a)
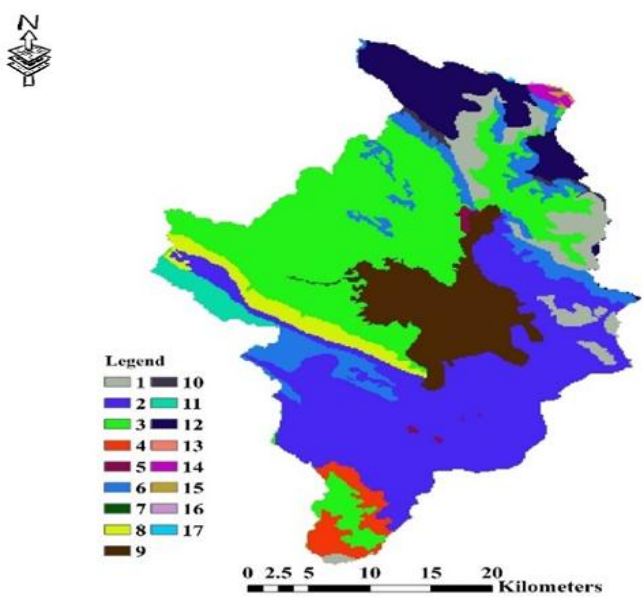

(b)

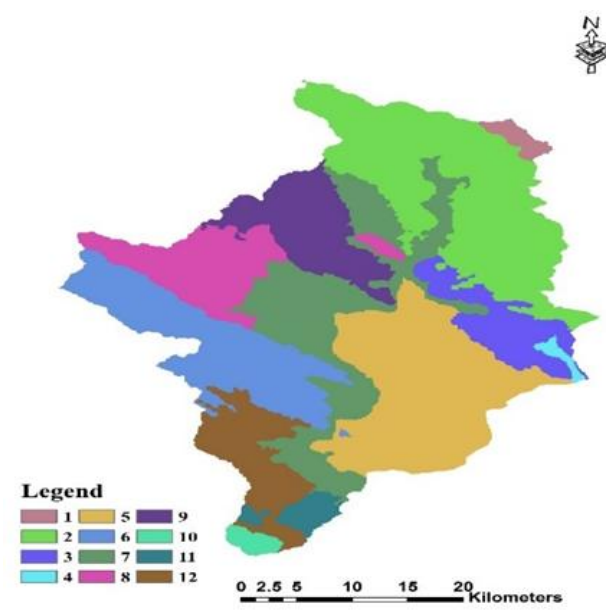

(c)

Figure 2. (a) Digital elevation, (b) land use and (c) soil maps of Ravansar Sanjabi basin 


\section{Satellite Data}

\section{Modis Snow Cover Maps}

Snow Cover Area (SCA) is one of the important input variables of SRM model for simulating the runoff. The snow cover area maps of MODIS Satellite (provided by National Snow and Ice Data Center; Hall et al., 2002) make it possible to study the daily snow distribution (Jain et al., 2009). In this research MOD10A2 (Hall et al., 2002), which includes 8-day maximum snow cover maps with resolution of $500 \times 500 \mathrm{~m}$, is used to determine daily SCA in 2002 and 2003. These images are then further converted into grid format and spatial reference of the Ravansar Sanjabi basin (WGS-1984-UTMzone-38N) and the daily Snow Cover Area variable is prepared accordingly by using linear interpolation between 8-day intervals of the images. Many studies (Prasad and Roy, 2005; Jain et al., 2009; Immerzeel et al., 2009; Bookhagen and Burbank, 2010; Tahir et al., 2011; Zhanget al., 2014; and Karimi et al., 2016) use SRM to simulate the daily runoff and they apply the snow cover maps of MODIS satellite to calculate the $S C A$ input variable for implementation of model.

\section{Principle and Methods}

\section{Snowmelt Runoff Model (SRM)}

SRM is a degree-day based, conceptual and deterministic model and can simulate and forecast the runoff from snow melt in basins. In this model, the basin can be classified into various elevation zones according to the maximum and minimum height of basin; and the input variables and necessary parameters can be entered into these zones for simulating the runoff. The input variables of model include daily precipitation data, maximum and minimum or average daily air temperature, Snow Cover Area $(S C A)$ and the daily runoff data for comparison of simulated runoff in the studied statistical period. In this study, Ravansar Sanjabi basin is divided into 5 elevation zones, with its characteristics shown in Table 4.

Table 4. Area zones and their informations in Ravansar Sanjabi basin

\begin{tabular}{ccccc} 
Zone ID & $\begin{array}{c}\text { Elevation ranges } \\
(\boldsymbol{m})\end{array}$ & $\begin{array}{c}\text { Zone area } \\
\left(\mathbf{K m}^{2}\right)\end{array}$ & $\begin{array}{c}\text { Hypsometric zone } \\
\text { elevation }(\boldsymbol{m})\end{array}$ & $\begin{array}{c}\text { Number of } \\
\text { meteorological } \\
\text { stations available } \\
\text { in zone }\end{array}$ \\
\hline 1 & $1309-1600$ & 858.22 & 1454 & 3 \\
2 & $1600-1900$ & 233.06 & 1794.5 & 1 \\
3 & $1900-2200$ & 89.46 & 2049.5 & 0 \\
4 & $2200-2500$ & 41.16 & 2349.5 & 0 \\
5 & $2500-2755$ & 5.47 & 2605.25 & 0 \\
\hline
\end{tabular}

Due to the lack of number and distribution of hydro-meteorological stations for rainfall and temperature data in each elevation zone, the data of hydro-meteorological stations are extended to higher elevation zones by the relationship between rainfall and temperature gradient with height for the statistical years of 2002 to 2003 . Other input 
variables are $S C A$ and runoff; the $S C A$ of each elevation zone is calculated through snow cover images from MOD10A2 of MODIS satellite. Fig. 3 shows the Snow Cover Area in each studied elevation zone in Ravansar Sanjabi basin during 2002 and 2003.

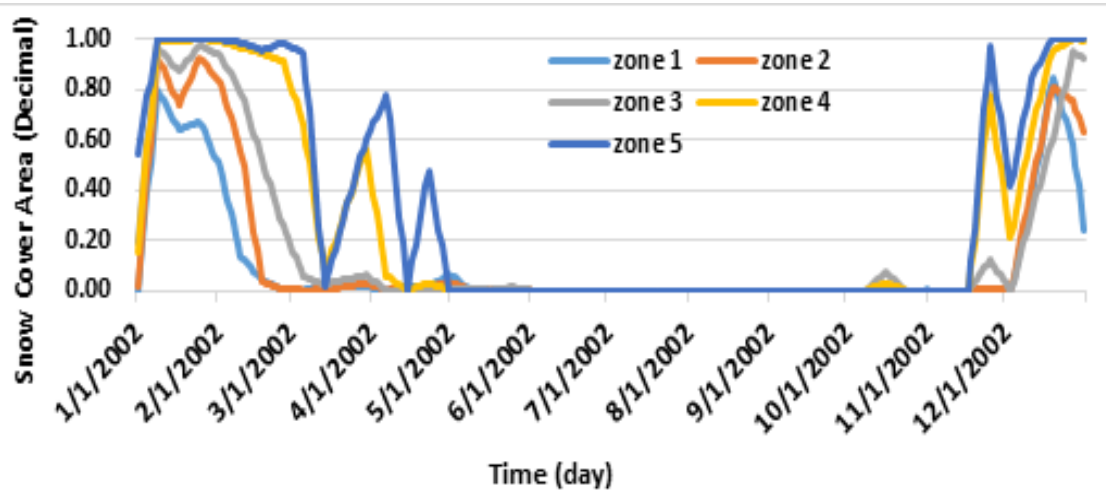

(a)

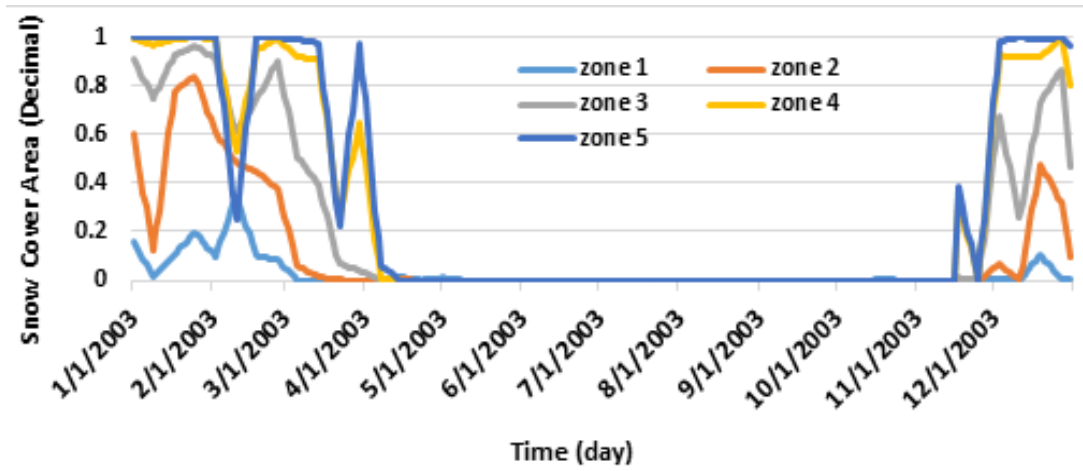

(b)

Figure 3. Snow cover area distribution in elevation zones of Ravansar Sanjabi basin calculated from MODIS Daily snow cover images (MOD10A2) over (a) January 01, 2002 to December 31, 2002 and (b) January 01, 2003 to December 31, 2003

Furthermore, the daily runoff data is obtained from Doab Merek station statistics which are related to Gareh Sou River and basin output during the statistical period of 2002 to 2003. The runoff in SRM is calculated per equation 1.

$$
Q_{n+1}=\left[C_{s n^{*}} \cdot a_{n}\left(T_{n}+\Delta T_{n}\right) S_{n}+C_{R n} P_{n}\right] \frac{A \cdot 10000}{86400}\left(1-K_{n+1}\right)+Q_{n} K_{n+1}
$$

$Q$ : Average daily discharge $\left(m^{3} s^{-1}\right), C_{S}$ : Snow runoff coefficient (decimal), $C_{R}$ : Rain runoff coefficient (decimal), $a$ : degree-day factor $\left({ }^{\circ} \mathrm{C} d a y^{-1}\right), T$ : Base station temperature $\left({ }^{\circ} \mathrm{C}\right), \Delta T$ : Difference between temperature in base station and corresponding site with average hypsometric height of basin or elevation bar $\left({ }^{\circ} \mathrm{C}\right), S$ : Ratio of snow cover to entire basin (decimal), $P$ : Rainfall which contributes to runoff $(\mathrm{cm}), A$ : Area of basin or selected site $\left(\mathrm{km}^{2}\right), n$ : Number of days during the predicted or simulated period, $K$ : Recession coefficient which indicates the discharge reduction rate in a period of time without effects of snow or rain according to equation 2. 


$$
K=\frac{Q_{n+1}}{Q_{n}}
$$

The main SRM parameters by which the model can be calibrated include the critical temperature $\left(T_{C R I T}\right)$; the degree-day factor $(a)$; Temperature Lapse Rate $(\gamma)$; runoff coefficient including the runoff from rain coefficient $\left(C_{R}\right)$; and runoff coefficient from snow melt $\left(C_{S}\right)$; rainfall contributing area $(R C A)$; recession coefficient $(K)$ and $x$ and $y$ parameters; and Lag Time $(L)$. In this study, the runoff of Ravansar Sanjabi basin during 2002 and 2003 is simulated through WINSRM 1.12 which is the Windows version of SRM model.

\section{SWAT Model (Soil and Water Assessment Tool)}

SWAT model is a continuous, conceptual and distributed model which performs the hydrological simulation in basins through various data such as weather, topography, soils, land use and land cover. SWAT model uses the water balance equation to simulate the hydrological processes in basins according to equation 3 .

$$
\Delta S W=\sum_{i=1}^{t}\left(R_{\text {day }}-Q_{\text {surf }}-E_{a}-W_{\text {se日p }}-Q_{\text {gw }}\right)
$$

In this equation, $\triangle S W$ : changes of water stored in soil; $R_{\text {day }}$ : rainfall; $Q_{\text {surf: }}$ amount of surface runoff; $E_{a}$ : actual evapotranspiration, $W_{\text {seep }}$ : amount of water penetrated into unsaturated soil zone; and $Q_{g w}$ : groundwater flow which joins the river are all in daily time scale (Mengistu, 2009). The Hydrologic Response Unit (HRU) is the smallest unit in this model and its hydrological characteristics are obtained from combination of DEM, land use and basin soil maps. The water in soil, surface runoff, sediment and chemical elements are first calculated for each HRU and then for each sub-basin and eventually the whole basin (Hosseini, 2014). In this study, the slope is categorized according to the slope map of the studied basin (Fig. 4) in 5 classes.

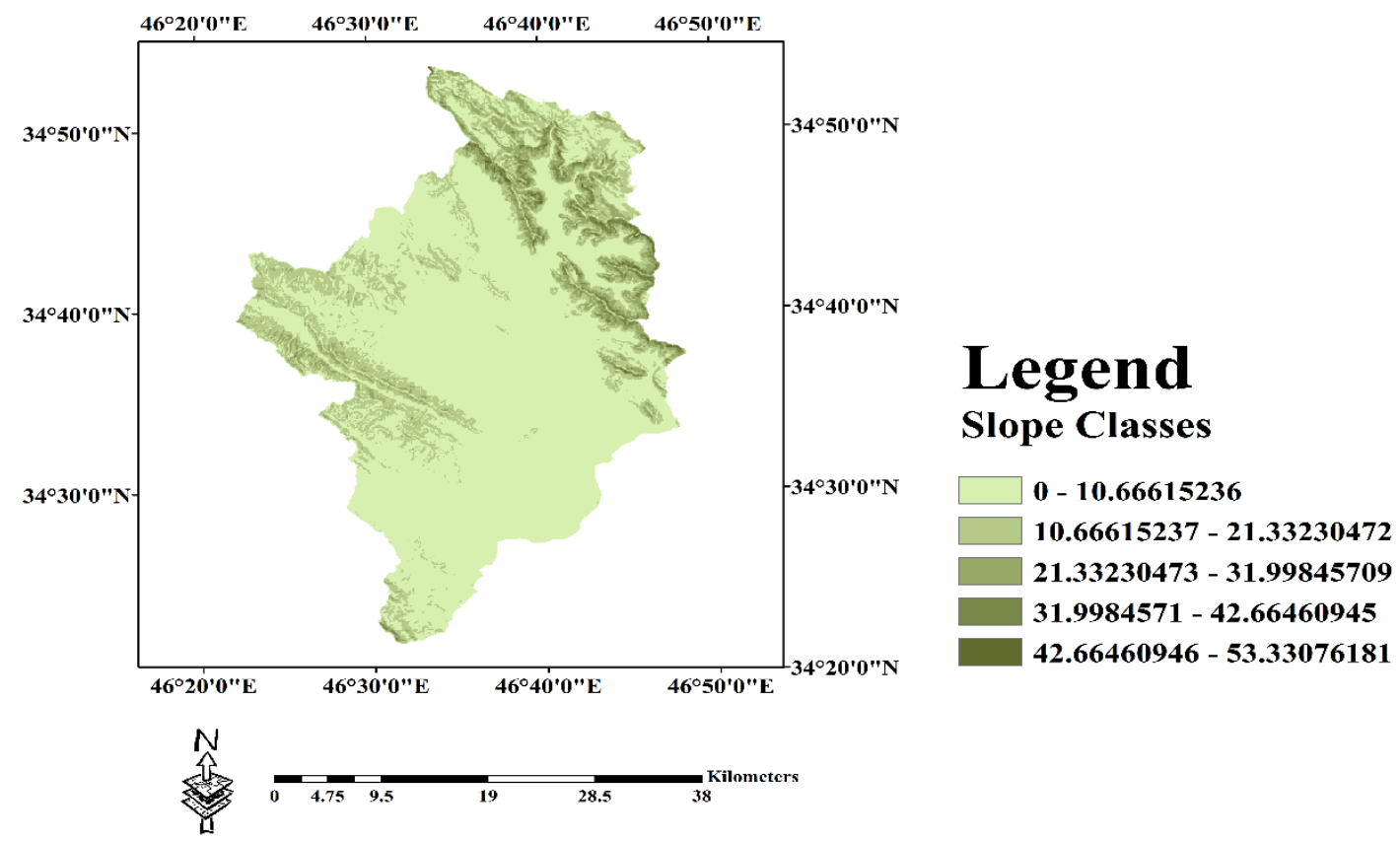

Figure 4. The slope map of Ravansar Sanjabi basin 


\section{Calibration and Validation of Models}

In this research, the calibration period of models is 2002 (January 1 of 2002 to December 31 of 2002), and validation period is 2003 (January 1 of 2003 to December 31 of 2003). There are several studies such as Fierz et al., 2003; Xue et al., 2003; Garen and Marks, 2005; Safari Shad et al., 2013; Vafakhah et al., 2014; Karimi et al., 2016, that have been done with 1-3 years of data for runoff simulation through hydrological models. Calibration of SRM is manually done by the changes in model parameters (by comparing the simulated and measured hydrographs of flow and trial and error) and SWAT model calibration are done by SUFI2 algorithm in SWAT-CUP 2012 software version 5.1.6 (Abbaspour et al., 2004). In the next step of calibration period, the models are validated by optimized parameters.

\section{Evaluation of Models}

The evaluation of SRM model is done by the help of two statistical indices, namely the coefficient of determination $\left(R^{2}\right)$ and the volume difference $(D v)$ (Martinec et al., 2008) and the equations for calculation of these indices are presented in formulas 4 and 5.

$$
\begin{gathered}
R^{2}=\frac{\left[\sum_{i}\left(Q_{m, i}-\bar{Q}_{m}\right)\left(Q_{s, i}-\bar{Q}_{s}\right)\right]^{2}}{\sum_{i}\left(Q_{m, i}-\bar{Q}_{m}\right)^{2} \sum_{i}\left(Q_{s, i}-\bar{Q}_{s}\right)^{2}} \\
D_{V}=\frac{V_{R}-\bar{V}_{R}}{V_{R}}
\end{gathered}
$$

In equation $4, \overline{Q_{m}}$ : the measured mean discharge, $\overline{Q_{s}}:$ the simulated mean discharge, $Q_{m, i}:$ the measured discharges, and $Q_{s, i}:$ the simulated discharges are all in $\mathrm{m}^{3} \mathrm{~s}^{-1}$. In equation $5, V_{R}$ is the measured runoff volume $\left(\mathrm{m}^{3}\right)$ and $V_{R}$ is the volume of simulated runoff $\left(\mathrm{m}^{3}\right)$ during the statistical period. If the simulated and measured values are equal, $R^{2}$ value is equal to 1 (Abbaspour et al., 2007). In addition to these two indices in evaluation of daily runoff simulation conducted by SRM and SWAT models, NashSutcliffe coefficient (Nash and Sutcliffe, 1970) is assessed as the third index. The formula for calculating this index is according to equation 6.

$$
N S E=1-\frac{\sum_{i}\left(Q_{m, i}-Q_{s i}\right)^{2}}{\sum_{i}\left(Q_{m, i}-\overline{Q_{m}}\right)^{2}}
$$

In this equation, $\overline{Q_{m}}$ is the measured mean discharge, $Q_{s i}$ is the simulated discharge and $Q_{m, i}$ is the measured discharge values during simulation period, all of them in $\mathrm{m}^{3} \mathrm{~s}^{-1}$. Table 5 shows the model performance based on NSE index values.

Table 5. Model performance ratings for NSE (Moriasi et al., 2007; Kult et al., 2014)

\begin{tabular}{cc}
$\boldsymbol{N S E}$ statistic & Rating \\
\hline $0.75<N S E \leq 1.00$ & Very good \\
$0.65<N S E \leq 0.75$ & good \\
$0.5<N S E \leq 0.65$ & Satisfactory \\
$N S E \leq 0.50$ & Unsatisfactory \\
\hline
\end{tabular}




\section{Results and Discussion}

\section{Runoff Simulation by SRM Model in Calibration and Validation Periods}

As mentioned, in this research the daily runoff for a two-year period (2002-2003) are simulated by SRM and SWAT models. The first year of this period is considered for calibration of models, and the second year for validation. Fig. 5 shows the hydrographs of simulated and observed daily flow in Ravansar Sanjabi basin through SRM Model during the calibration and validation periods.

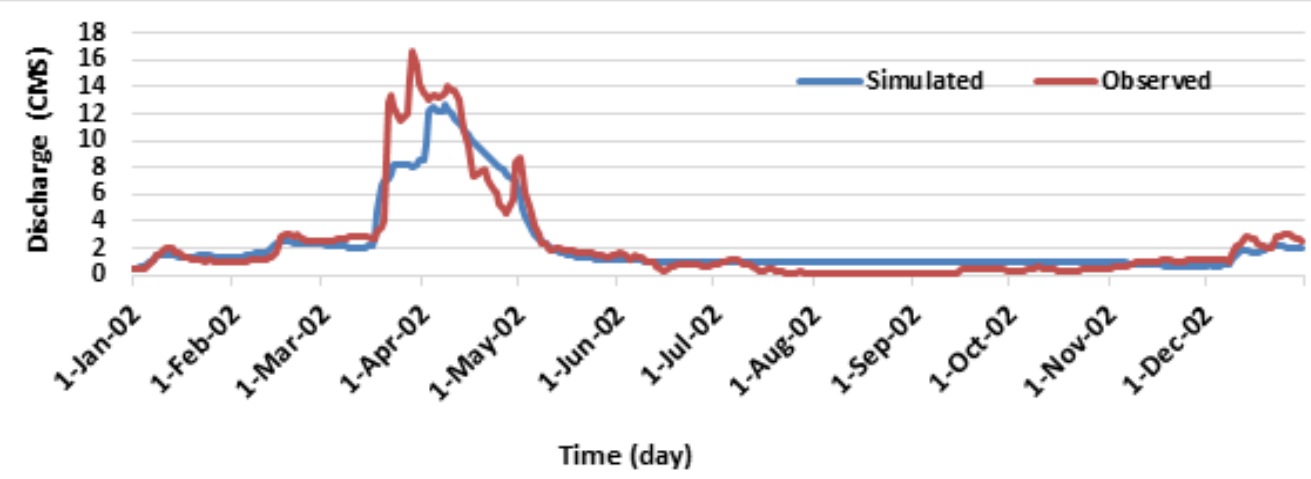

(a)

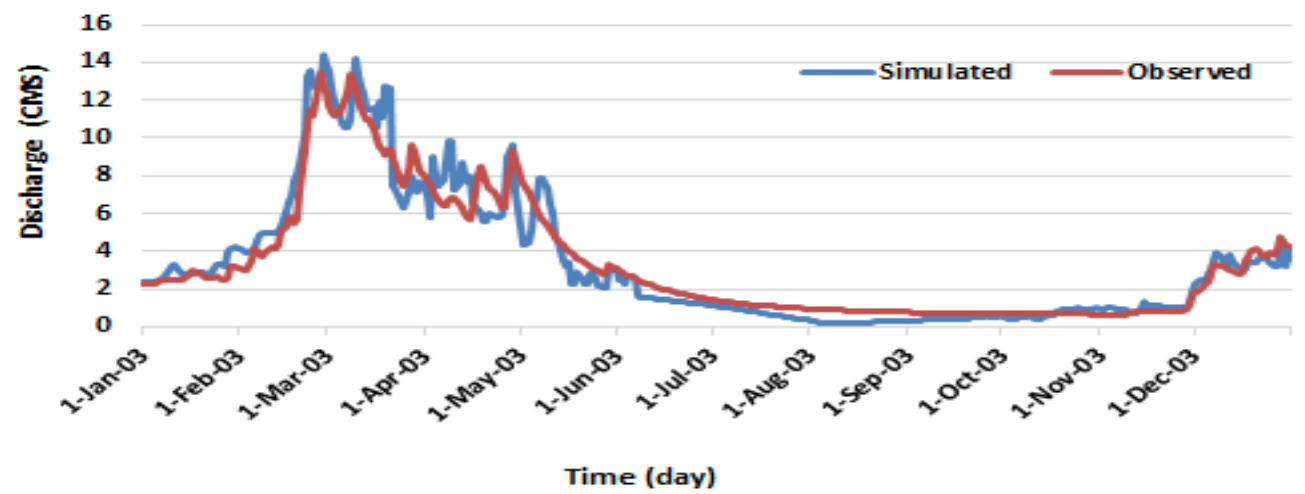

(b)

Figure 5. Simulated and observed daily runoff data using SRM model during (a) calibration, and (b) validation periods

According to Fig. 5, SRM simulates the maximum values of runoff lower than its measured values in calibration period (Fig. 5a.). The peak of observed hydrograph during the calibration period belongs to March 29 of 2002, and its discharge in this day is $16.6 \mathrm{~m}^{3} \mathrm{~s}^{-1}$, while the simulated discharge rates in the corresponding day is $8.06 \mathrm{~m}^{3} \mathrm{~s}^{-1}$. This errors may be attributed to generalizing the precipitation or temperature to each elevation zone through Rainfall and temperature gradient with height relationship, measuring the flow recession coefficient parameters or the values of rain and snow runoff coefficient or errors in recording historical hydro-meteorological data of Ravansar Sanjabi basin. Simulated hydrograph by SRM model and observed values in validation period (Fig. 5b.) have a good compliance during this stage and the pick and 
low values of measured runoff are well simulated by model. Table 6 represents the results of runoff simulation by SRM according to statistical evaluation criteria in calibration and validation periods.

Table 6. Calculated values of statistics indicators in calibration and validation stage using SRM model

\begin{tabular}{ccc} 
Evaluation indicator & Calibration year (2002) & Validation year(2003) \\
\hline$N S E$ & 0.9 & 0.95 \\
$D_{v}$ & -0.01 & -0.01 \\
$R^{2}$ & 0.86 & 0.93 \\
\hline
\end{tabular}

Table 6 indicates that the SRM model has properly simulated the daily runoff both in calibration and validation periods, with the NSE coefficient being higher than 0.75 in both periods. The volume difference of observed and simulated flow $\left(D_{v}\right)$ is equal to -0.01 in both calibration and validation periods of SRM and this indicates the negligible volume difference of simulated and observed flow during these two periods. Table 7 presents the total flow volume and average simulated discharge during the calibration and validation periods of SRM model as well as the total observed flow volume and average observed discharge in these periods.

Table 7. Total flow volume and Average discharge simulated by SRM model in calibration and validation periods

\begin{tabular}{ccccc} 
Runoff values & \multicolumn{2}{c}{ Calibration year(2002) } & \multicolumn{2}{c}{ Validation year (2003) } \\
\hline & Simulated & Observed & Simulated & Observed \\
Total runoff volume $\left(10^{6} \mathrm{~m}^{3}\right)$ & 71.730 & 71.717 & 106.003 & 105.998 \\
Average discharge $\left(\mathrm{m}^{3} \mathrm{~s}^{-1}\right)$ & 2.275 & 2.274 & 3.361 & 3.361 \\
\hline
\end{tabular}

Table 7 clearly indicates the slight difference $\left(0.001 \mathrm{~m}^{3} \mathrm{~s}^{-1}\right)$ in the average of simulated and observed discharge during the calibration period (2002). For the validation period (2003) even better results are obtained and the simulated and observed discharge rates are identical. Fig. 6 shows the correlation of simulated and observed data for daily runoff for both the calibration and validation periods.

Comparison of simulated and observed data in Fig. 6, show that there is an appropriate correlation between these data, with the coefficients of determination $\left(R^{2}\right)$ being 0.86 and 0.93 in calibration (Fig. 6a.) and validation (Fig. 6b.) periods, respectively, as mentioned earlier in (Table 6). 


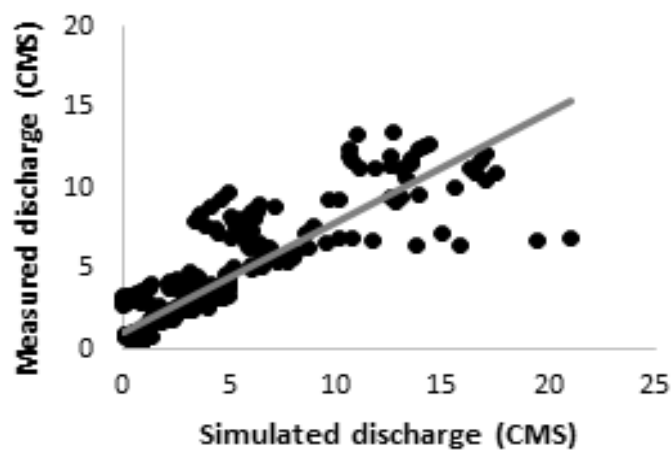

(a)

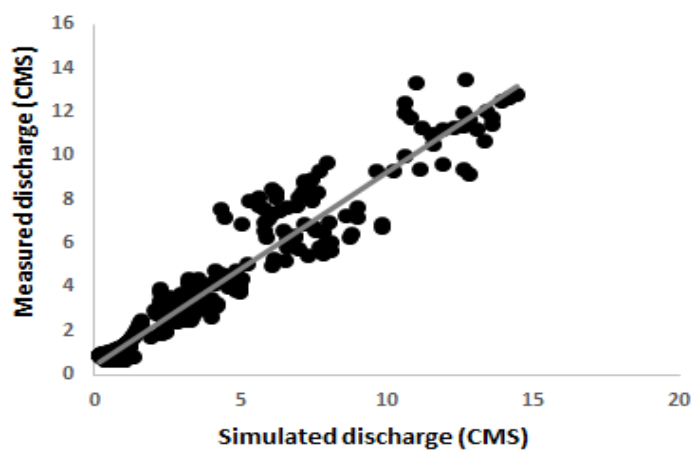

(b)

Figure 6. Correlation of the simulated daily runoff by SRM model and daily observed values in the (a) calibration (2002) and (b) validation (2003) periods

\section{Runoff Simulation by SWAT Model in Calibration and Validation Periods}

The provision of Digital Elevation Map (DEM) for the studied region and determination of the sub-basins by the model is the first step in implementing the SWAT model. Fig. 7 shows the sub-basins and river network of Ravansar Sanjabi basin determined by SWAT model.

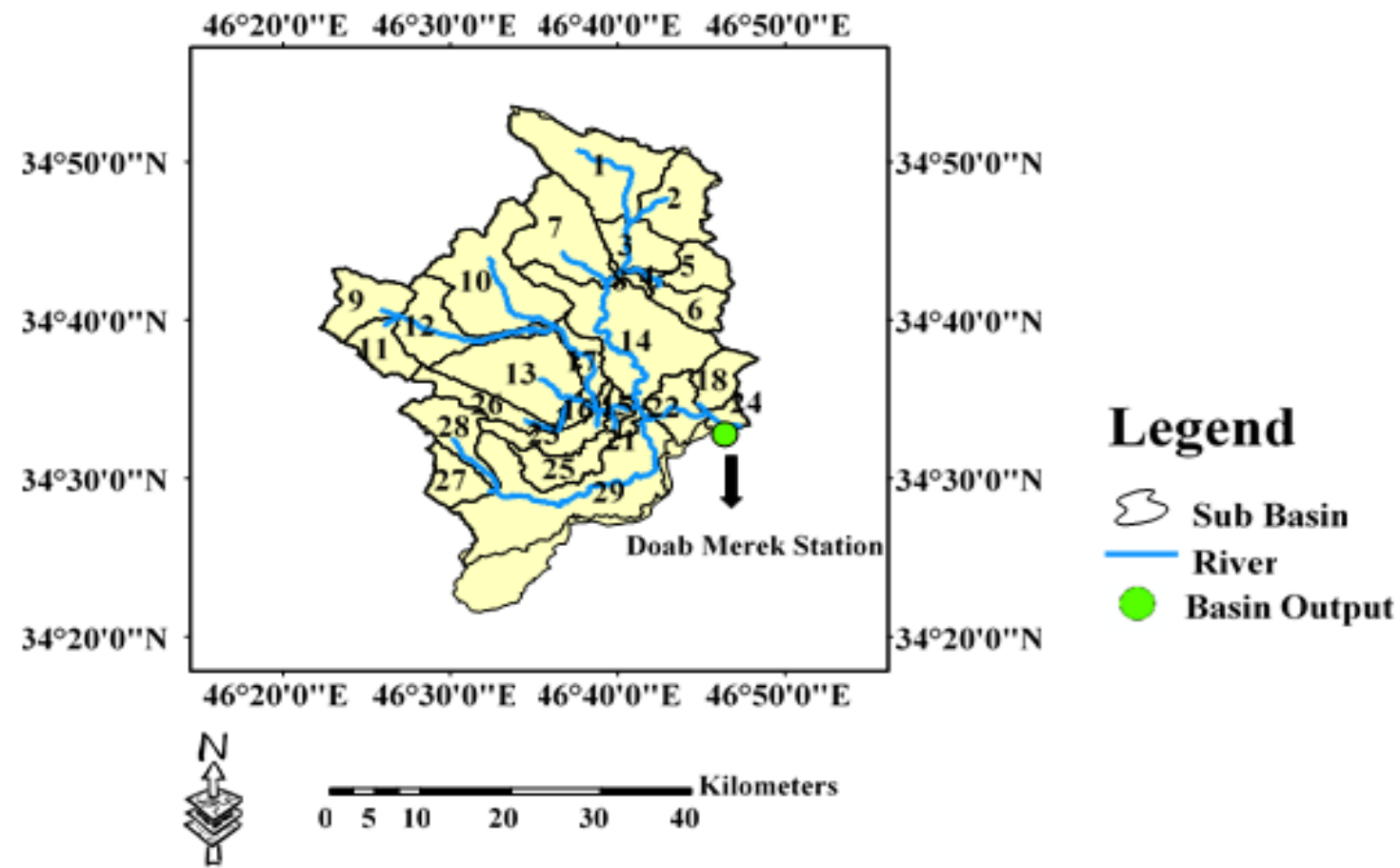

Figure 7. Sub-basins and Ravansar Sanjabi's river network determined by SWAT model

According to spatial reference of Doab Merk station (Table 1), the sub-basin number 24 is considered as the output of basin, and the data of Gareh Sou River in this station indicate the runoff from the whole Ravansar Sanjabi basin. The Hydrologic Response 
Units (HRU) are determined in Ravansar Sanjabi basin by combining three maps of soil, land use and DEM of basin (Fig. 2) and classification of slope in 5 classes (Fig. 4), as shown in Fig. 8.

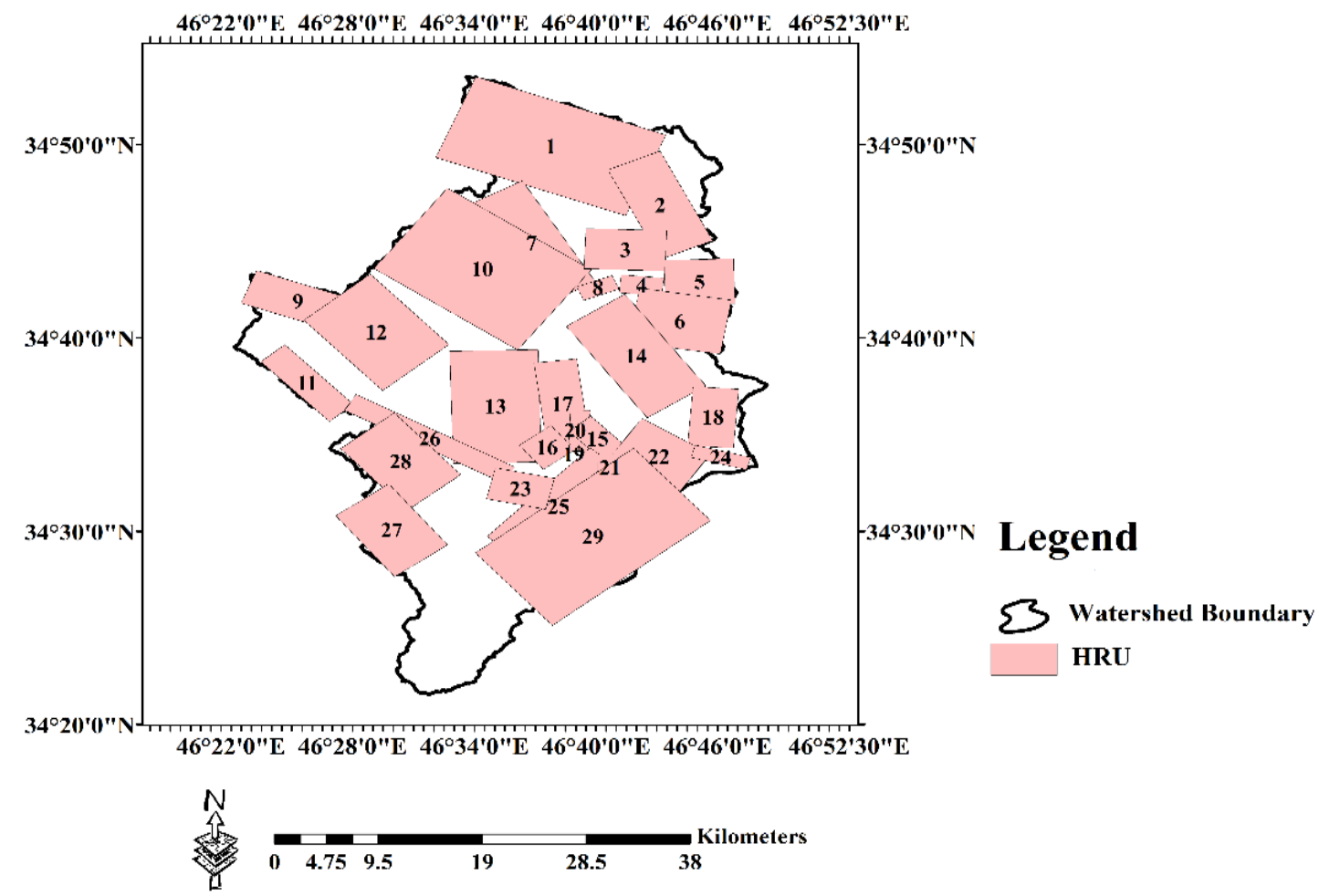

Figure 8. Specified HURs by SWAT model in Ravansar Sanjabi basin

According to Fig. 8, 29 HRUs are determined for studied basin by the SWAT model. The meteorological data is introduced to model after provision of HRU maps. The meteorological data, which is entered into the model, include the long-term statistical characteristics and parameters necessary for Ravansar synoptic station at monthly time scale; furthermore, the data of rainfall, maximum and minimum temperatures, wind speed, solar radiation, and relative humidity of existing synoptic and meteorological stations in basin (Table 1) are all at daily time scale during 2002 to 2003. Fig. 9 shows the hydrographs of simulated daily flow by the SWAT model and the observed daily flow during the both calibration (2002) and validation (2003) periods.

Fig. 9 indicates that in the SWAT model simulations, an appropriate correlation is not observed with the observed flow hydrograph in terms of maximum and minimum values of runoff and also with the rising and recession limbs of the observed hydrographs in both calibration (Fig. 9a.) and validation (Fig. 9b.) periods. The selected statistical criteria using the SWAT model for both the calibration and validation periods are shown in Table 8. 


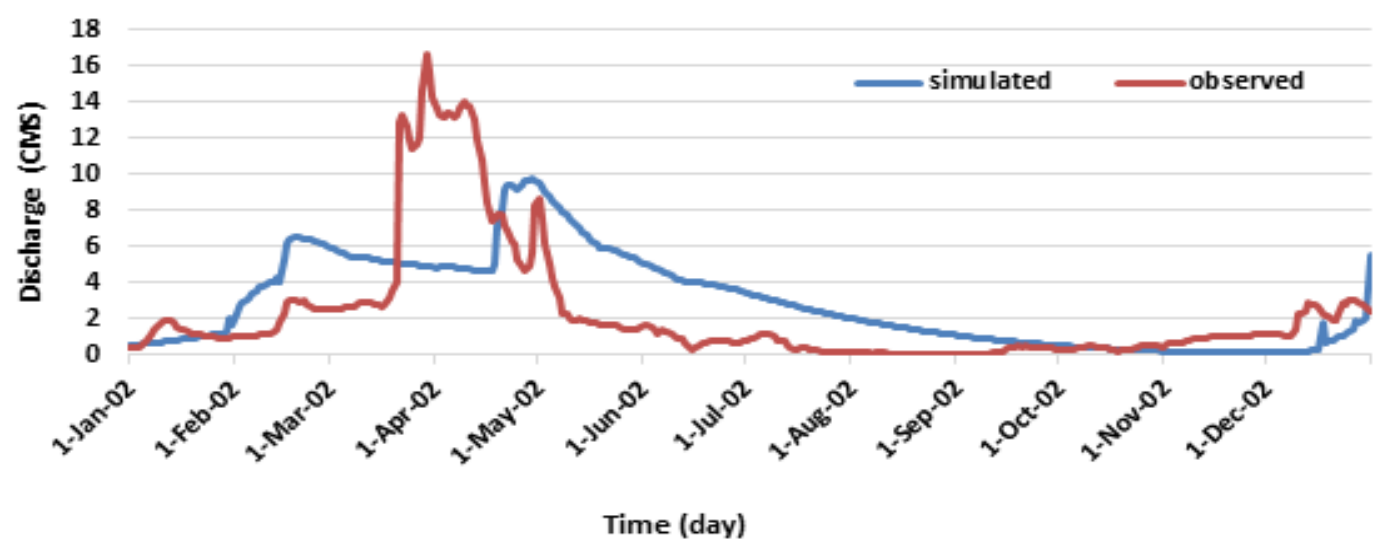

(a)

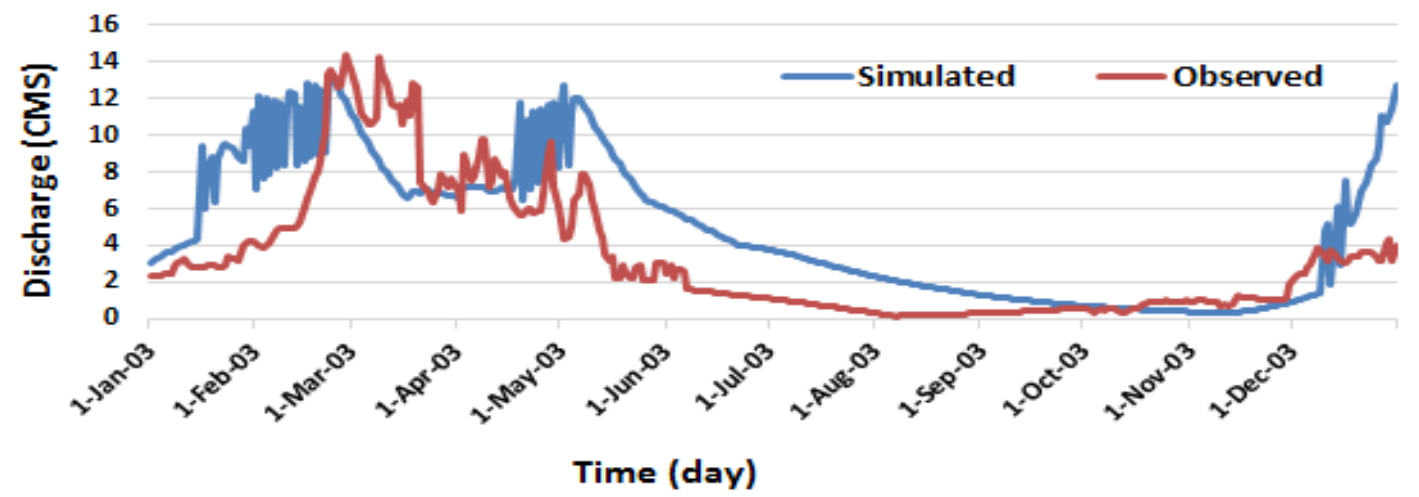

(b)

Figure 9. Simulated and observed daily runoff data using SWAT model during (a) calibration, and (b) validation periods

Table 8. Calculated values of statistics indicators in calibration and validation stage using SWAT model

\begin{tabular}{ccc} 
Evaluation indicator & Calibration year(2002) & Validation year (2003) \\
\hline$N S E$ & 0.14 & 0.16 \\
$D_{v}$ & -0.27 & -0.46 \\
$R^{2}$ & 0.24 & 0.39
\end{tabular}

According to Table 8, the SWAT model presents weak results in simulation of daily runoff in Ravansar Sanjabi basin such that the NSE coefficient equal to 0.14 and 0.16 in calibration and validation periods, respectively. Table 9 represents the total volume of flow and average simulated discharge by the SWAT model, and also the total volume of flow and average observed discharge during calibration and validation periods.

According to Table 9, the SWAT model overestimates the total volume of flow in both calibration and validation periods. Furthermore, the average simulated daily discharge for calibration and validation periods are different from average observed values in these periods, especially in validation period. Fig. 10 shows the dispersion of simulated data by SWAT model and observed data in calibration and validation periods. 
Table 9. Total flow volume and Average discharge simulated by SWAT model in calibration and validation periods

Runoff values Calibration year (2002) Validation year (2003)

\begin{tabular}{ccccc}
\hline & Simulated & Observed & Simulated & Observed \\
Total runoff volume $\left(10^{6} \mathrm{~m}^{3}\right)$ & 91.821 & 71.717 & 154.749 & 105.998 \\
Average discharge $\left(\mathrm{m}^{3} \mathrm{~s}^{-1}\right)$ & 2.91 & 2.274 & 4.90 & 3.361 \\
\hline
\end{tabular}

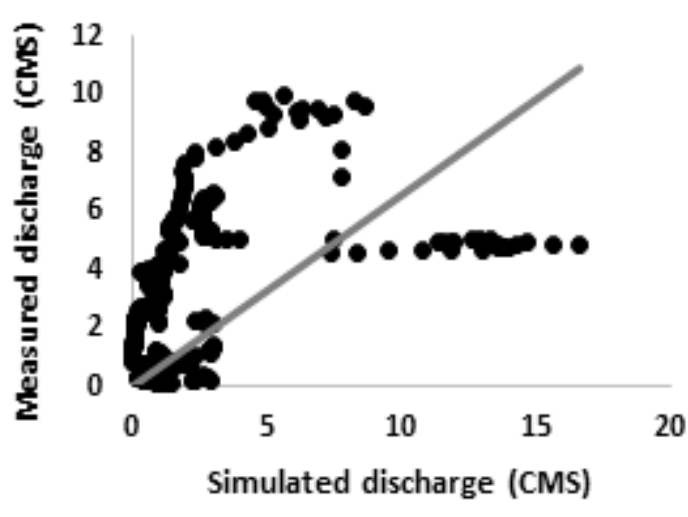

(a)

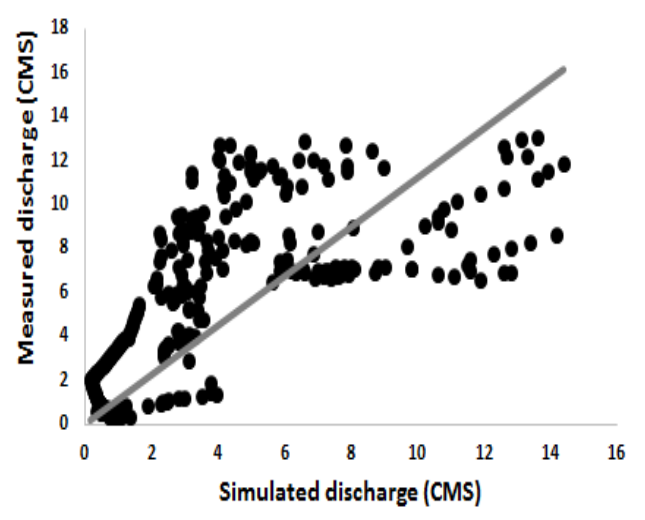

(b)

Figure 10. Correlation of the simulated daily runoff by SWAT model and daily observed values in the (a) calibration and (b) validation periods

According to Fig. 10, there is not an appropriate correlation between simulated and observed data of runoff both in calibration (Fig. 10a.) and validation (Fig. 10b.) periods, with coefficients of determination $\left(R^{2}\right)$ being 0.24 and 0.39 , respectively (Table 8$)$.

\section{Summary and Conclusions}

In current work the daily runoff in Ravansar Sanjabi basin is simulated by means of the SWAT and SRM models, and results are compared. These models are evaluated in terms of daily runoff simulation through statistical criteria to select the most suitable model. Results of current research shows that the SRM has better performance than the SWAT model both in validation and calibration periods, such that Nash-Sutcliffe coefficients are 0.9 and 0.95 for calibration and validation periods, respectively. The NSE coefficients are equal to 0.14 and 0.16 in calibration and validation periods for the SWAT model, respectively and this indicates the unsatisfactory simulation of model. The volume difference of simulated and measured flow by SRM is $-1 \%$ in calibration and validation periods and this indicates the negligible difference between the simulated and observed volume values; however, the volume difference of simulated flow by SWAT model and measured values in calibration and validation periods are higher and equal to $-27 \%$ and $-46 \%$, respectively. Results show that the simulated data by SRM has 
better correlation with the observed data both in calibration and validation periods, such that the coefficients of determination $\left(R^{2}\right)$ are equal to 0.86 and 0.93 , respectively and 0.24 and 0.39 for SWAT model. Hydrograph of simulated flow by SRM in a 2-year calibration and validation periods has much better compliance with hydrograph of observed flow, such that the low observed flow is properly simulated by the model, while the hydrographs of simulated and observed flow of SWAT model do not correlate neither in calibration nor in validation periods. According to obtained results of this study, since Ravansar Sanjabi is a mountainous basin and there is permanent snow in periods of precipitation in selected elevation zones (from January to May and also November and December of 2002 and 2003), the snow melt runoff has an important impact on daily flow in Gareh Sou river; and thus, SRM is more efficient and leads to more accurate results than SWAT model for simulation of daily runoff in this basin. This can be attributed to the fact that the SRM model considers the snow cover area obtained from snow satellite images as a direct input parameter and that it is able to distinguish snow melt and rain runoff. In the SWAT model, on the other hand, the snow data is indirectly integrated into the model based on the critical temperature (which is used to categorize precipitation as snow or rain) and the rainfall-elevation gradient. This can lead to the errors observed in the runoff simulation of the Ravansar Sanjabi basin using SWAT model. Therefore, for areas where snow melt runoff plays an important role, and where the snow melt runoff makes up the majority of the total runoff, such as mountainous regions, it is recommended to use the SRM model for daily runoff estimations.

\section{REFERENCES}

[1] Abbaspour, K. C., Johnson, A. C., Van Genuchten, T. H. M. (2004): Estimating uncertain flow and transport parameters using a sequential uncertainty fitting procedure. - Vadose Zone Journal 3: 1340-1352.

[2] Abbaspour, C., Yang, J., Maximov, I., Siber, R., Bogner, K., Mieleitner, J., Zobrist, J., Srinivasan, R. (2007): Modelling hydrology and water quality in the prealpine alpine Thur watershed using SWAT. - Journal of Hydrology 333: 413-430.

[3] Arnold, J. G., Srinivasan, R., Muttiah, R. S., Williams, J. R. (1998): Large Area Hydrologic and Assessment Part 1: Model Development. - Journal of the American Water Resources Association 34: 73-89.

[4] Arnold, J. G., and Fohrer, N. (2005): SWAT 2000: current capabilities and research opportunities in applied watershed modeling. - Hydrological Processes 19: 563-572.

[5] Bookhagen, B. and Burbank, D. W. (2010): Toward a complete Himalayan hydrological budget: spatiotemporal distribution of snowmelt and rainfall and their impact on river discharge. - Journal of geophysical research 115: 1-25.

[6] Feng, X. Z., Li, W. J., Shi, Z. T., Wang, L. H. (2000): Satellite snow cover monitoring and snowmelt runoff simulation of Manas River in Tianshan Region, China. - Remote Sensing Technology and Application 15: 18-21.

[7] Fierz, C., Riber, P., Adams, E.E., Curran, A.R., Fohn, P.M.B., Lehning, M., Pluss, C. (2003): Evaluation of snow-surface energy balance models in alpine terrain. - Journal of Hydrology 282: 76- 94.

[8] Fontaine, T. A., Cruickshank, T. S., Arnold, J. G., Hotchkiss, R. H. (2002): Development of a snowfall snowmelt routine for mountainous terrain for the soil water assessment tool (SWAT). - Journal of Hydrology 262: 209-223. 
[9] Garen, D.C., Marks, D. (2005): Spatially distributed energy balance snowmelt modelling in a mountainous river basin: estimation of meteorological inputs and verification of model results. -Journal of Hydrology 315: 126-153.

[10] Gomez-Landesa, E. and Rango, A. (2002): Operational snowmelt runoff forecasting in the Spanish Pyrenees using the snowmelt runoff model. - Hydrological Processes 16: 1583-1591.

[11] Hall, D. K., Riggs, G. A., Salomonson, V. V., DiGirolamo, N. E., Bayr, K. J. (2002): MODIS snow cover products. - Remote Sensing of Environment 83: 181-194.

[12] Hosseini, M., Ashraf, M. A. (2015): Application of the SWAT Model for Water Components Separation in Iran. Retrieved from http://www.springer.com/us/book/9784431555636

[13] Hosseini, M. (2014): Water balance simulation of Garahsou basin of Kermanshah province by using SWAT model. - Iranian Journal of Watershed Engineering and Management 6: 63-73.

[14] Immerzeel, W. W., Droogers, P., De Jong, S. M., Bierkens, M. P. (2009): large scale monitoring of snow cover and runoff simulation in Himalayan river basins using remote sensing. - Remote Sensing of Environment 113: 40-49.

[15] Jain, S. K., Goswami, A., Saraf, A.K. (2009): Role of elevation and aspect in snow distribution in Western Himalaya. - Water Resources Management 23: 71-83.

[16] Jain, S. K., Tyagi, S., Singh, V. (2010): Simulation of Runoff and Sediment Yield for a Himalayan Watershed Using SWAT Model. -Journal of Water Resource and Protection 2: 267-281.

[17] Karimi, H., Zeinivand, H., Tahmasebipour, N., Haghizadeh, A., Miryaghoubzadeh, M. (2016): Comparison of SRM and WetSpa models efficiency for snowmelt runoff simulation. - Environmental Earth Sciences 75: 664.

[18] Kult, J., Choi, W., Choi, J. (2014): Sensitivity of the Snowmelt Runoff Model to snow covered area and temperature inputs. - Applied Geography 55: 30-38.

[19] Kusre, B. C., Baruah, D, C., Bordoloi, P. K., Patra, S. C. (2010): Assessment of hydropower potential using GIS and hydrological modeling technique in Kopili River basin in Assam (India). - Applied Energy 87: 298-309.

[20] Lee, S., Klein, A. G., Over, T. M. (2005): A comparison of MODIS and NOHRSC snow cover products for simulating stream flow using the Snowmelt Runoff Model. Hydrological Processes 19: 2951-2972.

[21] Li, K. Y., Coe, M.T., Ramankutty, N., De Jong, R. (2007): Modeling the hydrological impact of landuse change in West Africa. - Journal of Hydrology 337: 258-268.

[22] Liu, W., Li, Z. L., Li, K. B. (2007): Snowmelt runoff modeling in Tashikuergan River Basin, Xinjiang, China. - Technical Supervision in Water Resources 3: 343-46.

[23] Ma, H., Cheng, G. D. (2003): A test of snowmelt runoff model (SRM) for the Gongnaisi River Basin in the western Tianshan Mountains. - Chinese Science Bulletin 48: 22532259.

[24] Martinec, J., Rango, A., Roberts, R. (2008): SRM Snowmelt Runoff Model, Users's Manual. New Mexico State University, Las Cruces, NM.

[25] Martinec, J. (1975): Snowmelt runoff Model for Stream flow forecast. - Nordic Hydrology 6: 145-154.

[26] Mengistu, K. T. (2009): Watershed Hydrological Responses to Changes in Land Use and Land Cover, and Management Practices at Hare Watershed, Ethiopia Universität Siegen, Research Institute for Water and Environment, Siegen, Germany.

[27] Mishra, A., Froebrich, j., and Gassman, P. W. (2007): Evaluation of the SWAT Model for Assessing Sediment Control Structures in a Small Watershed in India. -Transactions of the ASABE 50: 469-477.

[28] Moriasi, D. N., Arnold, J. G., Van Liew, M. W., Binger, R. L., Harmel, R. D., Veith, T. (2007): Model evaluation guidelines for systematic quantification of accuracy in watershed simulations. - Transactions of the ASABE 50: 885-900. 
[29] Motovilov, Y. G., Gottschalk, L., England, K., Rodhe, A. (1999): Validation of distributed hydrological model against spatial observations. - Agricultural and Forest Meteorology (98-99): 257-277.

[30] Murty, P. S., Pandey, A., and Suryavanshi, S. (2014): Application of semi distributed hydrological model for basin level water balance of the Ken basin of Central India. Hydrological Processes 28: 4119-4129.

[31] Nash, J. E., Sutcliffe, J. V. (1970): River flow forecasting through conceptual models part 1, a discussion of principals. - Journal of Hydrology 10: 282-290.

[32] Oeurng, C., Sauvage, S. and Sanchez Perez, J. M. (2011): Assessment of hydrology, sediment and particulate organic carbon yield in a large agricultural catchment using the SWAT model. - Journal of hydrology 401: 145-153.

[33] Peterson, J. R. and Hamlett, J. M. (1998): Hydrologic calibration of the SWAT model in a watershed containing fragipan soils. - American Water Resources Association 37: 295303.

[34] Prasad, V. H. and Roy, P. S. (2005): Estimation of snowmelt runoff in Beas Basin India. - Geocarto International 20: 41-47.

[35] Refsgaard, J. C. and Knudsen, J. (1996): Operational validation and intercomparison of different types of hydrological models. - Water resources research 32: 2189-2202.

[36] Rostamian, R., Jaleh, A., Afyuni, M., Mousavi, S. F., Heidarpour, M., Jalalian, A., Abbaspour, K. C. (2008): Application of a SWAT model for estimating runoff and sediment in two mountainous basins in central Iran. - Hydrological Sciences Journal 53: 977-988.

[37] Safari Shad, M., Habibnejad Roshan, M., Ildoromi, A. (2013): Integration of the MODIS Snow cover produced into snowmelt runoff modeling. - Journal of the Indian Society of Remote Sensing 42: 107-117.

[38] Sensoy, A., Uysal, G. (2012): The Value of snow depletion forecasting methods towards operational snowmelt runoff estimation using MODIS and numerical weather prediction data. - Water Resources Management 26: 3415-3440.

[39] Singh, V. P., Woolhiser, D. A. (2002): Mathematical Modeling of Watershed Hydrology. - Journal of Hydrological Engineering 7: 270-292.

[40] Sommerlot, A., Nejadhashemi, A., Woznicki, S., Giri, S., Prohaska, M. (2013): Evaluating the capabilities of watershed scale models in estimating sediment yield at field scale. - Journal of Environmental Management 127: 227-236.

[41] Spruill, C. A., Workman, S.R., Taraba, J. (2000): Simulation of daily and monthly stream discharge from small watersheds using the SWAT model. - Transactions of ASAE 43: 1431-1439.

[42] Tahir, A. A., Chevallier, P., Arnaud, Y., Neppel, L., Ahmad, B. (2011): Modeling snowmelt runoff under climate scenarios in the Hunza River basin, Karakoram Range, Northern Pakistan. - Journal of Hydrology 409: 104-117.

[43] Tekeli, A. E., Akyurek, Z., Sorman, A. A., Sensoy, A., Sorman, A. U. (2005): Using MODIS snow cover maps in modeling snowmelt runoff process in the eastern part of Turkey. -Remote Sensing of Environment 97: 216-230.

[44] Vafakhah, M., Nouri, A., Alavipanah, S. K. (2014): Snowmelt runoff estimation using radiation SRM model in Taleghan watershed. - Environmental Earth Sciences 73: 9931003.

[45] Varanou, E., Gkouvatsou, E., Baltas, E., Mimikou, M. (2002): Quantity and quality integrated catchment modeling under climate change with use of soil and water assessment tool model. - Journal of Hydrologic Engineering 7: 228-244.

[46] Wang, J. and Li, S. (2006): Effect of climate change on snowmelt runoffs in mountainous regions of inland rivers in Northwestern China. Science in China-Series D: - Earth Sciences 49: 881-888.

[47] Wurbs, R. A. (1998): Dissemination of generalized water resources models in the United States. - Water International 23: 190-198. 
[48] Xue, Y., Sun, S., Kahan, D.S., Jiao, Y. (2003): Impact of parameterizations in snow physics and interface processes on the simulation of snow cover and runoff at several cold region sites. - Journal of Geophysical Research 108: 8859.

[49] Zhang, G., Xie, H., Yao, T. (2014): Quantitative water resources assessment of Qinghai Lake basin using snowmelt runoff model (SRM). - Journal of Hydrology 519: 976-987.

[50] Zhang, P., Wang, J., Liu, Y., Li, Y. (2009): Application of SRM to flood forecasting and forewarning of Manasi River Basin in spring. - Remote Sensing Technology and Application 24: 456-461. 